\title{
Knee and hip radiographic osteoarthritis features: differences on pain, function and quality of life
}

\author{
Duarte Pereira $^{1,2}$ (D) Milton Severo ${ }^{1,2} \cdot$ Rui A. Santos $^{3} \cdot$ Henrique Barros $^{1,2}$ • \\ Jaime Branco ${ }^{4} \cdot$ Raquel Lucas $^{1,2} \cdot$ Lúcia Costa $^{5}$ • Elisabete Ramos ${ }^{1,2}$
}

Received: 21 January 2015 /Revised: 31 July 2015 / Accepted: 28 September 2015 /Published online: 7 October 2015

(C) International League of Associations for Rheumatology (ILAR) 2015

\begin{abstract}
The association between radiographic osteoarthritis $(\mathrm{OA})$ and symptoms is inconsistent and variable according to each joint. The purpose of this study is to understand the relation between radiographic OA features, pain, function and quality of life, in knee and hip joints. A cross-sectional study was performed using information from EPIPorto cohort. Data was obtained by interview using a structured questionnaire on social, demographic, behavioural and clinical data. Pain was assessed using a pain frequency score (regarding ever having knee pain, pain in the last year, in the last 6 months and in the last month). Quality of life was evaluated with Short Form 36 (SF-36) and function disability with the Lequesne knee and hip indexes. Radiographic knees and hips were classified using the Kellgren-Lawrence score (KL $0-4$ ). Linear regression and proportional odds ratios estimated the association between radiographic features, pain, function and quality of life. In our study, symptomatic $\mathrm{OA}$ ( $\mathrm{KL} \geq 2$ plus joint pain) was $26.0 \%$ in knee and $7.0 \%$ hip joints. In knee, the increase on radiographic score increased the odds to have a higher pain frequency score $[1.58(95 \% \mathrm{CI}=1.27,1.97)]$ and was
\end{abstract}

Duarte Pereira

duartefisio@hotmail.com

Milton Severo

milton@med.up.pt

Rui A. Santos

rui.andre@netcabo.pt

Henrique Barros

hbarros@med.up.pt

Jaime Branco

jaime.branco@fcm.unl.pt

Raquel Lucas

rlucas@med.up.pt associated [adjusted $\beta(95 \% \mathrm{CI})$ ] with worst general health $[-3.05(-5.00,-1.09)]$, physical function $[-4.92(-7.03$, $-2.80)]$, role-physical $[-4.10(-8.08,-0.11)]$, bodily pain $[-2.96(-5.45,-0.48)]$ and limitations in activities of daily living $[0.48(0.08,0.89)]$. Regarding hip, no significant associations were found between the severity of radiographic lesions and these measures. Radiographic lesions in knee were associated with higher complaints, as far as pain and functional limitations are concerned, compared with hip.

Keywords Disability $\cdot$ Hip $\cdot$ Knee $\cdot$ Osteoarthritis $\cdot$ Pain . Quality of life

\section{Introduction}

Osteoarthritis (OA) is the most common age-related disease and is the major cause of pain and locomotor disability worldwide [1]. OA is a complex joint disease characterized by focal cartilage loss, new bone formation and involvement of all joint

Lúcia Costa

dias.costa.ml@gmail.com

Elisabete Ramos

eliramos@med.up.pt

1 Department of Clinical Epidemiology, Predictive Medicine and Public Health, University of Porto Medical School, 4200-319 Porto, Portugal

2 EPI Unit, Public Health Institute, University of Porto, Porto, Portugal

3 Hospital Beatriz Ângelo, Loures, Portugal

4 CEDOC, Nova Medical School/Faculdade de Ciências Médicas, Rheumatology Department, Universidade Nova de Lisboa, CHLO, EPE—Hospital Egas Moniz, Lisboa, Portugal

5 Rheumatology Department, EPE-Hospital S. João, Porto, Portugal 
tissues [2]. Gradual radiographic evidence of joint damage and an increase in the amount of complaints are indicators of OA progression. However, similar radiographic patterns could bring on different complaints [3].

Knee OA is more prevalent than hip OA, but the difference on these estimates changes according to the OA definition used, with differences becoming larger when symptomatic $\mathrm{OA}$ is considered and lower when the definition is based only on radiographic lesions [4]. Since radiographic knee and hip OA expresses objective joint physiopathological changes [5, 6], differences on the disease prevalence by joint site could be related with differences on the expression and evaluation of the complaints [7].

Discordance between pathology, symptoms and disability is frequently found in OA [8]. This discordance suggests that there are determinants of signs and symptoms in this disorder other than radiographic severity [9]. Gender, age, body mass index, co-morbidities, psychosocial status, anthropometrics and muscle strength are some of the aspects that should be understood when analysing these associations [10-12].

Although both knee and hip are weight-bearing joints, they have a different anatomy and different biomechanical actions and functions. It can be expected that similar radiographic scores can be associated with different patterns of complaints in knee and hip $[1,13,14]$. Independently of the joint affected, pain and functional impairments are the key domains of OA complaints, and taken together, they often exert a significant reduction in quality of life [15].

Understanding how different hip and knee complaints according to radiographic findings are can help to perceive the differences between these joints in OA case ascertainment and management [13, 16-18].

The purpose of this study is to understand the relation between radiographic OA features, pain, function and quality of life, in knee and hip joints.

\section{Methods}

\section{Data collection}

The study was performed using information collected as part of the EPIPorto cohort [19]. Briefly, this cohort evaluates noninstitutionalized adults, resident in Porto, an urban centre located in northwest Portugal with almost 400,000 inhabitants. Participants were selected by random digit dialling and invited to visit the Department of Clinical Epidemiology, Predictive Medicine and Public Health, at the University of Porto Medical School, for an evaluation, which included an interview based on a structured questionnaire on social, demographic, behavioural and clinical data. The proportion of participation at recruitment was $70 \%$.
The local ethics committee of S. João Hospital, a university hospital, approved the study protocol. All participants gave written consent to participate in the study, which was carried out in accordance with the Helsinki Declaration.

We used the Strengthening the Reporting of Observational Studies in Epidemiology (STROBE) guidelines in the planning and execution of this study.

\section{General data collection}

Between 2005 and 2008, the first follow-up was performed and data was collected by trained interviewers using structured questionnaires plus a physical examination.

We evaluated marital status (categorized on two categories: married/civil union and single/divorced/widow), years of education (measured as the number of successfully completed years of formal schooling), occupation (white collar, blue collar and other, including students, unemployed and those who never had a job) and current occupational status (working, retired and other). Based on self-reported diagnosis, we also evaluated as dichotomous variables (yes/no) the presence of chronic diseases in general and a previous diagnosis of knee and hip OA.

Knee and hip pain were evaluated using a set of "yes/no" questions. Firstly, participants were asked if they "ever had knee pain not related with any trauma or injury?" and if they "ever had hip pain not related with any trauma or injury?" If participants gave a positive answer, they were asked to answer (yes/no) to three further questions on each joint: "In the last year, did you have more than three pain episodes?"; "During the last 6 months did pain last longer than a week?"; and "During the last month did you have pain?" Pain intensity was also measured using the visual analogue pain scale (VAS) (0 to $100 \mathrm{~mm}$ ) [20] for each joint and all time frames evaluated by the questions (at the moment, in the last year, in the last 6 months and in the last month); however, this information did not improve the ability of the score to classify participant's pain [21]. The Portuguese version of the Beck Depression Inventory (BDI) was used to evaluate depressive symptoms. It is composed of 21 items, evaluating symptoms and attitudes, covering emotions, behavioural changes and somatic symptoms in the previous 2 weeks before the evaluation. The final score ranges from 0 to 63 , with higher scores representing more severe depressive symptoms [22].

Quality of life was evaluated using the Portuguese version of the Medical Outcomes Study Short Form 36 (SF-36) that contains 36 items that cover eight subscales: physical function, role-physical, bodily pain, general health, vitality, social function, role-emotional and mental health [23].

Body weight was measured, by trained interviewers, to the nearest $0.1 \mathrm{~kg}$ using a digital scale (SECA $\left.{ }^{\circledR}\right)$, and height was measured to the nearest centimetre using a wall stadiometer 
$\left(\mathrm{SECA}^{\circledR}\right)$; then, BMI [weight $(\mathrm{kg}) /$ height $\left(\mathrm{m}^{2}\right)$ ] was estimated.

\section{Rheumatologist evaluation}

A few days after the first interview, a structured clinical evaluation by a rheumatologist took place. Participants were invited for rheumatologist evaluation if they fulfilled at least one of the four following criteria: (1) had visited a physician because of their pain in the previous year and had been prescribed any complementary diagnostic exam or treatment; (2) had had more than three pain episodes in the last year with an intensity score $\geq 60 \mathrm{~mm}$ in the visual analogue pain scale; (3) had had at least one pain episode in the previous month with, at least, 1week duration; (4) had had pain in the last month and a score $\geq 60 \mathrm{~mm}$ in the visual analogue pain scale [24]. During the visit to the rheumatologist, specific clinical data was obtained and a physical exam was performed.

The Lequesne index for knee OA and/or for hip OA was also completed for those participants that reported knee or/and hip pain in the last week. Both knee and hip Lequesne index versions included the measurement of pain (five questions), walking distance (one question) and activities of daily living (ADL) (four questions). The scores range from 0 (no pain, no disability) to 24 (maximum pain and disability) [25]. Points are allocated according to response so that higher values indicate greater severity [26].

\section{Knees and hip radiographs}

Weight-bearing antero-posterior [1] and lateral, semi-flexed ( $45^{\circ}$ flexion) [27] radiographs of knees were obtained. For hips, standard antero-posterior weight-bearing radiographs [28] were taken. Radiographs were graded according to the Kellgren-Lawrence scale (KL): grade 0, none: no visible features of OA; grade 1, doubtful: questionable osteophytes or questionable joint space narrowing; grade 2, minimal: definitive small osteophytes, little/mild joint space narrowing; grade 3 , moderate: definitive moderate osteophytes, joint space narrowing of at least $50 \%$; grade 4 , severe: joint space impaired severely, cysts and sclerosis of subchondral bone [6]. For knee radiographs, a KL score $(0-4)$ was attributed in tibiofemoral (medial and lateral) and patello-femoral of the right and left knees. A global KL score (0-4) was attributed to each hip.

\section{Participants}

From the 2485 participants of the EPIPorto cohort that participated at the baseline evaluation, 1682 were re-evaluated during the follow-up performed between 2005 and 2008. From those, the first 1000 were systematically invited to do knee and hip radiographs and 907 were evaluated, but 231 participants had unreadable or incomplete radiographic evaluation for knee and/or hip. The final sample comprises the remained 676 participants with radiographic evaluation both on knee and hip OA (Fig. 1).

From these 676 participants, 241 had criteria to perform the rheumatologist evaluation and all did the evaluation. From those 241 participants, 81 participants answered the Lequesne index for knee and 43 for hip. As shown in Table 1, participants included were less educated and had a lower proportion of females.

\section{Data analysis}

Continuous variables were described by mean (standard deviation (SD)) for variables presenting a normal distribution and by median (25th-75th percentile) for skewed distributions. Comparisons were tested using chi-squared for proportions and Student's $t$ test or Mann-Whitney test for continuous variables according to their distribution.

The dimensionality and internal consistency of "pain questions/score" for each joint were assessed by factor analysis for dichotomous variables (latent trait model) and Cronbach's alpha, respectively. Principal component analysis was used to identify patterns of radiographic knee and hip OA features. Radiographic scores used were computed separately for knee and hip, by the numeric mean of the scores of the compartments evaluated in each joint. Linear regression and proportional odds ratios were calculated to estimate the association between radiographic features, pain, disability and quality of life.

Data analysis was performed using $\mathrm{R}^{\circledR}$ statistical software, and we considered the significance level at $5 \%$.

\section{Results}

Among the 676 participants considered in this cross-sectional analysis, the prevalence of radiographic lesions $(\mathrm{KL} \geq 2$ in at least one location of right or left joint) was $46.8 \%$ in knee and $24.1 \%$ in hip; $15.4 \%$ participants had both knee and hip radiographic OA. Among those with knee radiographic lesions, $55.5 \%$ reported ever having pain; regarding hip, this proportion was $28.9 \%$. Similar prevalence of radiographic findings were found in right and left sides both in knee and hip. In knee joints, $21.3 \%$ of participants had radiographic $\mathrm{KL} \geq 2$ in right medial tibio-femoral compartment, $22.7 \%$ in left knee medial tibio-femoral, $23.9 \%$ in right knee lateral tibio-femoral, $20.7 \%$ in left knee lateral tibio-femoral, $38.1 \%$ in right knee patelo-femoral and $36.9 \%$ in left knee patelo-femoral joint. Of the participants, $17.9 \%$ presented right hip $\mathrm{KL} \geq 2$ and $18.4 \%$ had left hip $\mathrm{KL} \geq 2$.

In order to summarize the radiographs' classification, we performed a principal component analysis considering all 
Fig. 1 Flow diagram of study participants

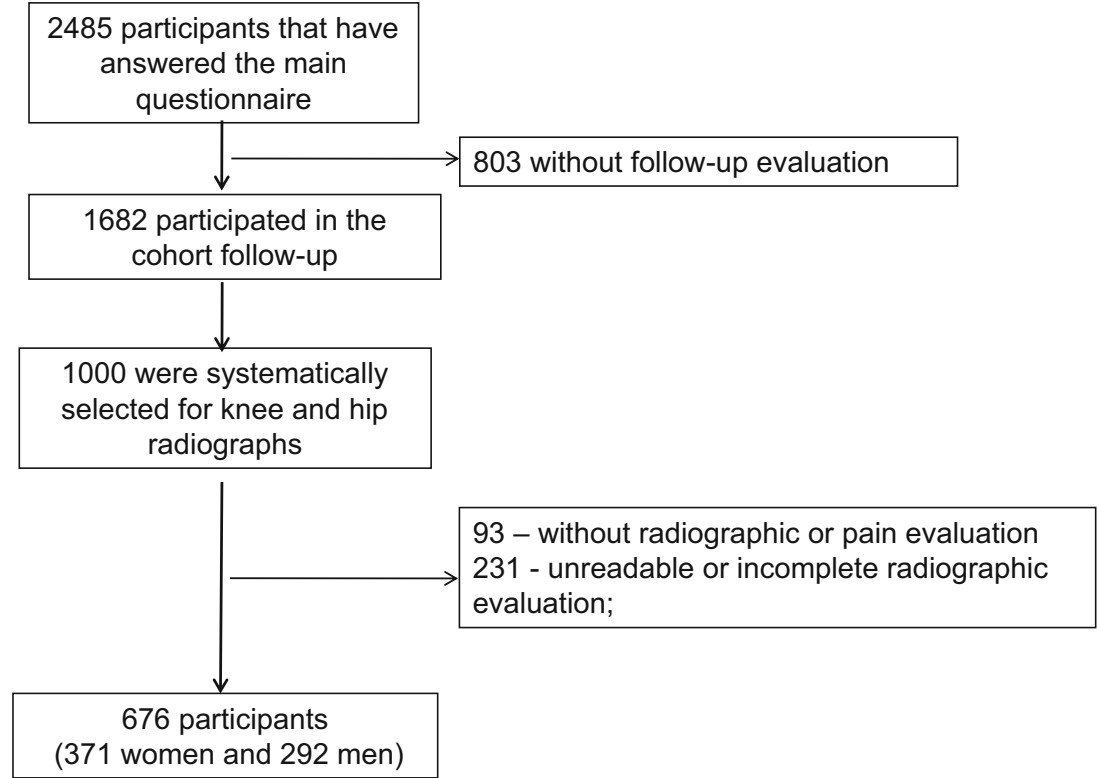

joint compartments evaluated for each joint. This analysis identified only one component both for knee and hip (Table 2). Therefore, we calculated the mean of the six radiographic aspects evaluated on knee (right and left) and the mean of the two aspects evaluated for hip (right and left), and we used these values as a score of the radiographic lesions on each joint for further analysis. The mean (SD) of the radiographic score was $0.97(0.83)$ for knee and $0.73(0.70)$ for hip.

Factor analysis was used to understand how to summarize the data obtained in the pain frequency questions (dichotomous variables), separately for each joint (Table 2). We identified only one factor for knee and one for hip and all items showed acceptable factor loading and global Cronbach's alpha scores, so we decided to consider these items as a pain frequency score for knee and a score for hip (where an increase in score representing an increase in pain frequency). Participants were classified in four categories: having no pain (score -1 ); having pain but no other positive answer (score 0 ); and score 1 , score 2 or score 3 , according to the number of positive answers, as a measure of pain frequency.

Figure 2 presented the distribution by pain scores, according with the radiographic scores $(<2$ and $\geq 2)$, by joint, and statistical differences were tested by qui-square. As expected, in both joint sites, we found higher pain scores among those with radiographic scores $\geq 2$, but considering each same category of radiographic score, pain complaints regarding knee were significantly higher than complaints related with hip.

After adjusting for age, gender, BMI and BDI, in knee we found a significant increase on pain frequency score by the increase on the severity of the OA lesions measured by the radiographic score $[\mathrm{POR}=1.70$ (95\% CI (1.28-2.27)]. Regarding hip, no significant association was found between radiographic severity and pain complaints (Table 3).
Concerning the subscales of SF-36, after adjustment (once age, gender and BMI appear to make major changes in estimated coefficients), the increase in the severity of knee radiographic lesions was significantly associated $[\beta(95 \% \mathrm{CI})]$ with the decrease in physical function $[-4.92(-7.03$, $-2.80)]$, role-physical $[-4.10(-8.08,-0.11)]$, bodily pain $[-2.96(-5.45,-0.48)]$ and general health $[-3.05(-5.00$, $-1.09)$ ]. No statistically significant associations were found regarding hip radiographic findings (Table 4).

Among the subsample of 81 participants that answered the Lequesne index for knee, the mean (SD) total score was 9.3 (4.0). In crude analyses, higher radiographic score on knee was associated with higher Lequesne score for activities of daily life (ADL) and total score. However, after adjusted for age, gender and BMI, only the association with ADL remained statistically significant $[\beta=0.48$; (95\% CI 0.08 , $0.89)$ ]. Regarding the 43 participants that have answered the Lequesne index for hip, the mean (SD) total score was 8.7 (5.0) and no statistically significant associations were found (Table 5).

\section{Discussion}

In accordance with previous data [4], higher prevalence of radiographic and symptomatic OA were found for knee compared with hip.

In our study, radiographic features in knee are more associated with higher pain complaints, lesser quality of life and more disability compared with hip joint. In hip, there was no association of radiographic score with pain frequency score and the same happened both for SF-36 and Lequesne index dimensions. 


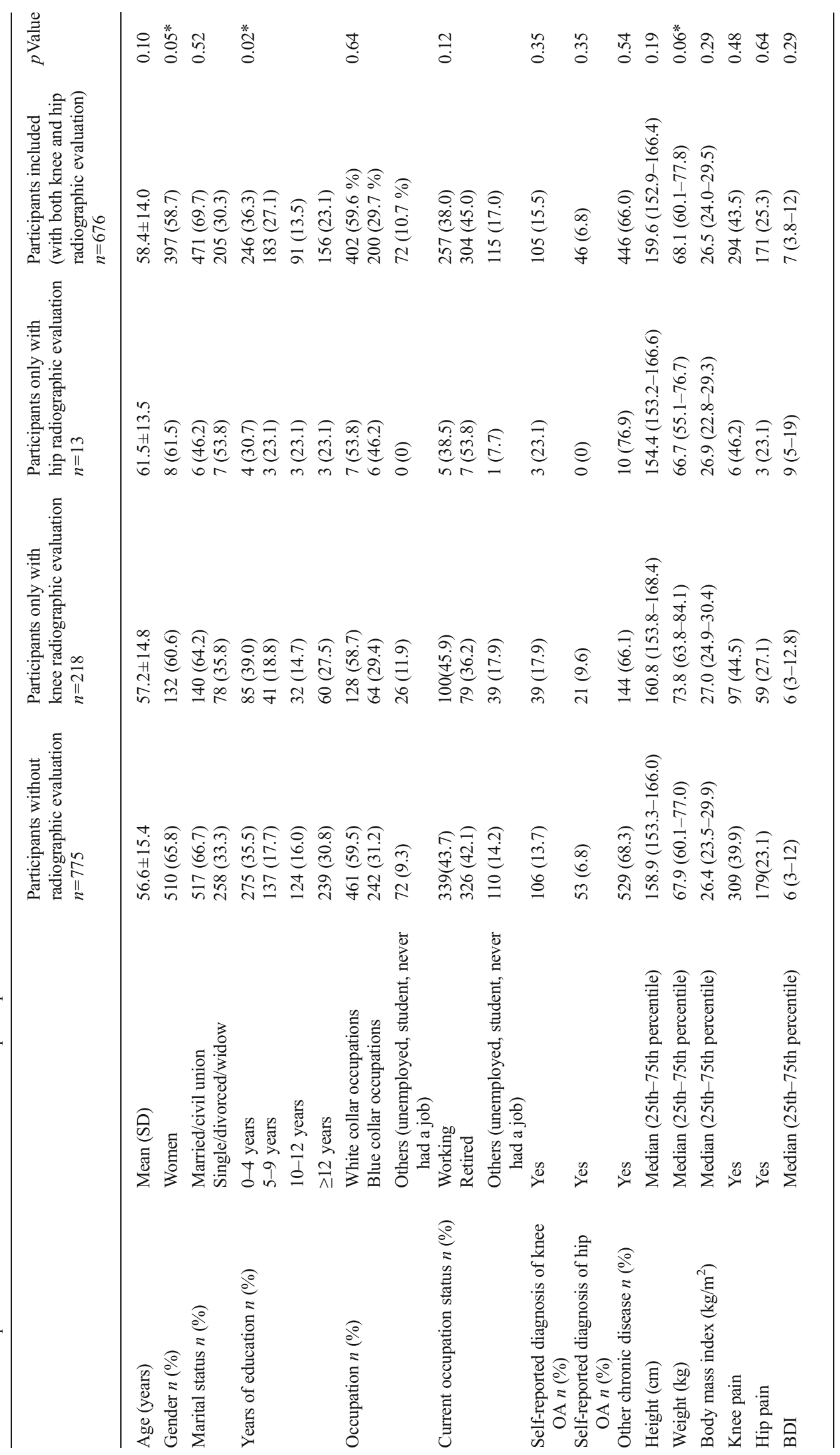


Table 2 Principal component/factor analysis for radiographic features and internal consistency/factor analysis for pain questions (dichotomous variables, latent trait model), both for knee and hip joints

\begin{tabular}{|c|c|c|c|c|}
\hline & Radiographic features & Component 1 & $\%$ of Variance explained & $\begin{array}{l}\text { Global Cronbach's } \\
\text { alpha }\end{array}$ \\
\hline \multirow[t]{6}{*}{ Knee } & Right knee medial tibio-femoral OA & 0.84 & \multirow{6}{*}{$67.0 \%$} & \multirow{6}{*}{0.90} \\
\hline & Left knee medial tibio-femoral OA & 0.82 & & \\
\hline & Right knee lateral tibio-femoral OA & 0.80 & & \\
\hline & Left knee lateral tibio-femoral OA & 0.83 & & \\
\hline & Right knee patelo-femoral OA & 0.82 & & \\
\hline & Left knee patelo-femoral OA & 0.81 & & \\
\hline \multirow[t]{3}{*}{ Hip } & Right hip OA & 0.92 & \multirow[t]{2}{*}{$84.2 \%$} & \multirow[t]{2}{*}{0.81} \\
\hline & Left hip OA & 0.92 & & \\
\hline & Pain questions & Factor loading & $\begin{array}{l}\text { Cronbach's alpha if } \\
\text { item deleted }\end{array}$ & Global Cronbach's alpha \\
\hline \multirow[t]{3}{*}{ Knee } & "In the last year, did you had more than three knee pain episodes?" & 0.97 & 0.51 & \multirow[t]{3}{*}{0.70} \\
\hline & "During the last 6 months, did knee pain lasted longer than a week?" & 0.86 & 0.74 & \\
\hline & "During the last month, did you had knee pain?" & 0.95 & 0.52 & \\
\hline \multirow[t]{3}{*}{ Hip } & "In the last year, did you had more than three hip pain episodes? & 0.99 & 0.44 & \multirow[t]{3}{*}{0.66} \\
\hline & "During the last 6 months, did hip pain lasted longer than a week? & 0.82 & 0.70 & \\
\hline & "During the last month, did you had hip pain?" & 0.90 & 0.53 & \\
\hline
\end{tabular}

The differences between knee and hip complaints can be explain by some aspects of the pathology of OA that are related to pain (e.g., synovitis or bone marrow edema) not seen in radiographs but can be present in different patterns of knee and hip OA. Differences in the radiographic evaluation can probably cause some of the differences found between knee and hip. We cannot exclude the hypothesis that the results for hip were consequence of a lack of power since lower prevalence of radiographic features was found for hip compared with knee.

Pain is an important marker of OA but also an unspecific symptom that may be associated with other conditions. One of the difficulties to study the relation of radiographic findings with pain is its assessment difficulty related to its fluctuating nature that can cause misclassification [29]. However, it is expected that higher radiographic lesions are associated with
Fig. 2 Knee and hip scores of pain frequency distribution according to radiographic score

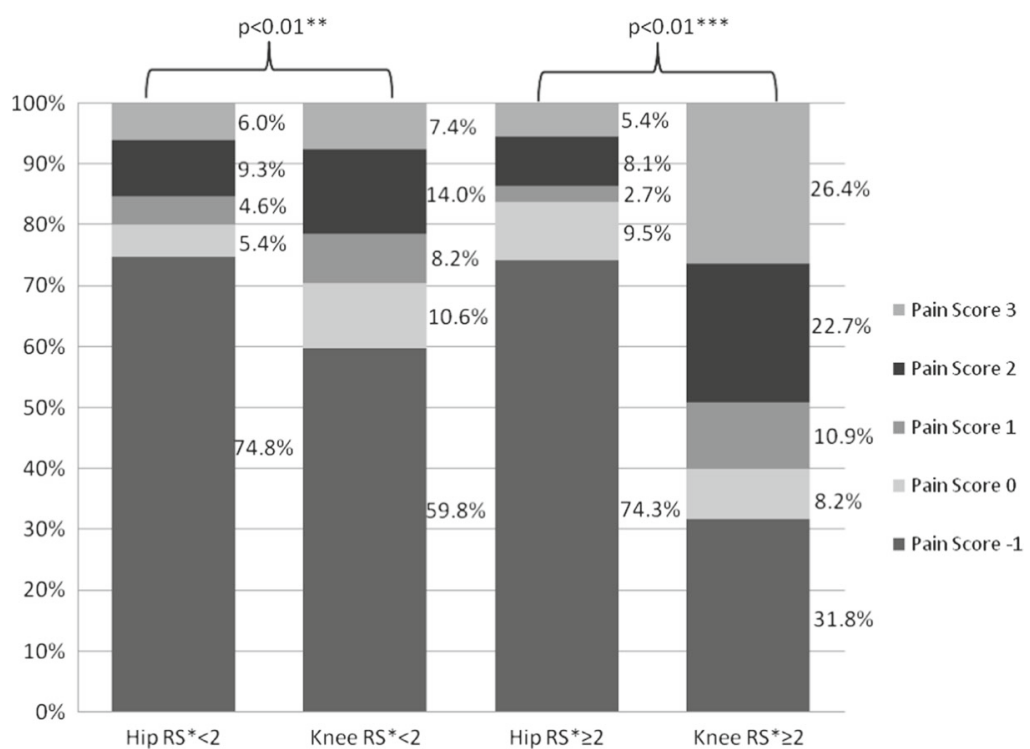

${ }^{*} \mathrm{RS}$ - Radiographic Score

${ }^{* *} p$ value for statistical differences between pain scores in knee and hip with radiographic score $<2$ ${ }^{* * *} p$ value for statistical differences between pain scores in knee and hip with radiographic score $>2$ 
Table 3 Association between radiographic score and pain score for knee and hip

\begin{tabular}{llll}
\hline & $\begin{array}{l}\text { Crude POR } \\
(95 \% \mathrm{CI})\end{array}$ & $\begin{array}{l}\text { Model 1 } \\
\text { POR }(95 \% \mathrm{CI})\end{array}$ & $\begin{array}{l}\text { Model 2 } \\
\text { POR (95 \% CI) }\end{array}$ \\
\hline Radiographic knee score & $\begin{array}{l}\text { Knee pain score } \\
2.08 *(1.73,2.51)\end{array}$ & $1.58^{*}(1.27,1.97)$ & $1.70 *(1.28,2.27)$ \\
Radiographic hip score & Hip pain score & & \\
& 1.22 & 1.07 & 1.09 \\
& $(0.97,1.52)$ & $(0.84,1.38)$ & $(0.78,1.52)$ \\
\hline
\end{tabular}

POR proportional odds ratio, Model 1 adjusted POR for age, gender and BMI, Model 2 model 1 plus BDI adjustment higher pain [14]. In our study that happened both for knee and hip supports the hypothesis that our pain "score" is measuring what is expected to measure. Our pain score was based in a small number of questions, without any hierarchy on complaints, created by a group of health professionals with field clinical expertise and that could be easily used in a clinical setting or in population-based studies [30].

The SF-36 is one of the most widely used instruments in the assessment of general health status including in OA [31]. We found that, although only regarding ADL, higher radiographic score was more associated with worst quality of life in knee compared with hip; in part, this could be mediated by the higher proportion of participants reporting pain in knee and it is known that pain is highly associated with OA patients' quality of life [32]. Other studies have focused in this issue, with poor associations between radiographic OA and quality of life; for example, in the study of Salaffi et al. [33], both in hip and knee, SF-36 dimensions were not influenced by the degree of radiographic severity.

In our study, only ADL score was associated with higher radiographic score in knee; no other statistically significant associations were found when Lesquesne index was used. These results may be consequence of a lake of power regarding hip since the prevalence of lesion is lower in this joint site and the number of participants with data for the Lesquesne index is small. We also need to recognize that the psychometric properties for the Portuguese versions are not fully studied, although the Lequesne indexes are one of the most widely used instruments for the assessment of OA-specific health status worldwide and have been used in different Portuguese OA studies [34]. Other validated instrument such as Western Ontario and McMaster osteoarthritis index (WOMAC) or Health Assessment Questionnaire (HAQ) could bring on different results and represent an important methodological improvement to a better understanding of this effect.

As far as radiographic evaluation is concerned, we evaluated six different points in the right and left knees, and for hip, we performed a measurement for the left and other for right side. For the purpose of our study and to allow statistical analysis, we estimated a mean score of all points evaluated in knee and hip (left and right). In true, the calculation of this score is not a validated outcome; however, principal component analysis identified only one component for radiographic features on both joints and no differences were found between radiographic disease severity in right and left sides for both knee and hip joints. Therefore, these results support the idea that the mean of all radiographic evaluations allowed, in this sample, a good summary measure of the radiographic lesions.

Duncan et al. [35] purposed that it is the severity of radiographic features within a joint, rather than its distribution between compartments, that is associated with symptoms. In part, this is probably due to the clustering of radiographic features of compartments within the same anatomical site, consistently with the known pathophysiology of the disease. This is also one of the reasons why we used a mean radiographic score to understand the association of radiographic features with pain, quality of life and function.

Our results might also be related to the radiographic procedures [8, 36] and the radiographic classification used [18]. In this study, we used the OA radiographic system developed by Kellgren and Lawrence [6]. Some reliability and validity limitations of this grading scale were described, with some authors considering it an imprecise method for radiographic measurement of OA and not sensitive enough for scientific work. One of the major concerns of this radiographic evaluation is the dependence on the analyser experience and the radiographic view(s) used. To minimize the potential errors, our radiographs were scored only by one specialist with a large experience and unaware of the participants' clinical data.

Knee radiographic features were evaluated in tibio-femoral (medial and lateral) and patelo-femoral of the right and left knee. For hip, only a global score was attributed. Although this is a frequent procedure, multiple evaluations increase the probability to detect changes; furthermore, radiographic features in knee-specific compartments may be easier to identify compared with the hip joint. Therefore, the use of more evaluation parameters in knee allows to obtain a more precise continuous outcome variable [18, 37]. These effects may contribute to the absence of associations between radiographic features and the studied consequences regarding hip.

One important limitation of this study is its cross-sectional design, which does not allow the exploration of how observed 
Table 4 Linear regression coefficients and $95 \%$ confidence intervals between radiographic OA score and SF-36, for knee and hip

\begin{tabular}{|c|c|c|c|c|c|c|c|c|}
\hline & \multicolumn{8}{|l|}{ SF-36 } \\
\hline & \multicolumn{2}{|l|}{ Physical function } & \multicolumn{2}{|l|}{ Role-physical } & \multicolumn{2}{|l|}{ Bodily pain } & \multicolumn{2}{|l|}{ General health } \\
\hline & $\begin{array}{l}\text { Crude } \beta \\
(95 \% \mathrm{CI})\end{array}$ & $\begin{array}{l}\text { Adjusted }^{\mathrm{a}} \beta \\
(95 \% \mathrm{CI})\end{array}$ & $\begin{array}{l}\text { Crude } \beta \\
(95 \% \mathrm{CI})\end{array}$ & $\begin{array}{l}\text { Adjusted } \beta^{\mathrm{a}} \\
(95 \% \text { CI) }\end{array}$ & $\begin{array}{l}\text { Crude } \beta \\
(95 \% \text { CI })\end{array}$ & $\begin{array}{l}\text { Adjusted } \beta^{\text {a }} \\
(95 \% \mathrm{CI})\end{array}$ & $\begin{array}{l}\text { Crude } \beta \\
(95 \% \mathrm{CI})\end{array}$ & $\begin{array}{l}\text { Adjusted } \beta^{\mathrm{a}} \\
(95 \% \mathrm{CI})\end{array}$ \\
\hline $\begin{array}{l}\text { Knee } \\
\quad \text { radiographic } \\
\text { score }\end{array}$ & $\begin{array}{l}-11.38^{*} \\
\quad(-13.32,-9.40)\end{array}$ & $\begin{array}{l}-4.92^{*} \\
\quad(-7.03,-2.80)\end{array}$ & $\begin{array}{l}-12.42^{*} \\
\quad(-15.96,-8.87)\end{array}$ & $\begin{array}{l}-4.10^{*} \\
\quad(-8.08,-0.11)\end{array}$ & $\begin{array}{l}-7.35^{*} \\
\quad(-9.65,-5.05)\end{array}$ & $\begin{array}{l}-2.96^{*} \\
\quad(-5.45,-0.48)\end{array}$ & $\begin{array}{l}-7.27^{*} \\
\quad(-8.99,-5.54)\end{array}$ & $\begin{array}{r}-3.05^{*} \\
\quad(-5.00,-1.09)\end{array}$ \\
\hline \multirow[t]{4}{*}{$\begin{array}{l}\text { Hip radiographic } \\
\text { score }\end{array}$} & $\begin{array}{l}-4.25^{*} \\
\quad(-6.74,-1.76)\end{array}$ & $\begin{array}{l}-0.06 \\
\quad(-2.39,2.27)\end{array}$ & $\begin{array}{l}-3.31 \\
\quad(-7.73,1.11)\end{array}$ & $\begin{array}{l}1.66 \\
\quad(-2.72,6.04)\end{array}$ & $\begin{array}{l}-1.08 \\
\quad(-3.81,1.65)\end{array}$ & $\begin{array}{l}0.58 \\
\quad(-2.07,3.23)\end{array}$ & $\begin{array}{l}-2.55^{*} \\
\quad(-4.70,-0.40)\end{array}$ & $\begin{array}{l}0.02 \\
\quad(-2.14,2.18)\end{array}$ \\
\hline & \multicolumn{8}{|l|}{ SF-36 } \\
\hline & \multicolumn{2}{|l|}{ Vitality } & \multicolumn{2}{|l|}{ Social function } & \multicolumn{2}{|l|}{ Role-emotional } & \multicolumn{2}{|l|}{ Mental health } \\
\hline & $\begin{array}{l}\text { Crude } \beta \\
(95 \% \mathrm{CI})\end{array}$ & $\begin{array}{l}\text { Adjusted } \beta^{\text {a }} \\
(95 \% \mathrm{CI})\end{array}$ & $\begin{array}{l}\text { Crude } \beta \\
(95 \% \mathrm{CI})\end{array}$ & $\begin{array}{l}\text { Adjusted } \beta^{\mathrm{a}} \\
(95 \% \mathrm{CI})\end{array}$ & $\begin{array}{l}\text { Crude } \beta \\
(95 \% \mathrm{CI})\end{array}$ & $\begin{array}{l}\text { Adjusted } \beta^{\mathrm{a}} \\
(95 \% \mathrm{CI})\end{array}$ & $\begin{array}{l}\text { Crude } \beta \\
(95 \% \mathrm{CI})\end{array}$ & $\begin{array}{l}\text { Adjusted } \beta^{a} \\
(95 \% \text { CI })\end{array}$ \\
\hline $\begin{array}{l}\text { Knee } \\
\quad \text { radiographic } \\
\text { score }\end{array}$ & $\begin{array}{l}-3.78^{*} \\
\quad(-5.65,-1.90)\end{array}$ & $\begin{array}{l}-0.87 \\
\quad(-2.98,1.25)\end{array}$ & $\begin{array}{l}-2.10 \\
\quad(-4.22,0.03)\end{array}$ & $\begin{array}{l}-0.78 \\
\quad(-3.24,1.68)\end{array}$ & $\begin{array}{l}-7.02^{*} \\
\quad(-10.67,-3.38)\end{array}$ & $\begin{array}{l}-1.26 \\
\quad(-5.47,2.94)\end{array}$ & $\begin{array}{l}-1.56 \\
\quad(-3.47,0.35)\end{array}$ & $\begin{array}{l}0.18 \\
\quad(-2.01,2.38)\end{array}$ \\
\hline $\begin{array}{l}\text { Hip radiographic } \\
\text { score }\end{array}$ & $\begin{array}{l}-0.22 \\
\quad(-2.44,2.00)\end{array}$ & $\begin{array}{l}0.79 \\
\quad(-1.46,3.03)\end{array}$ & $\begin{array}{l}-0.80 \\
\quad(-3.33,1.73)\end{array}$ & $\begin{array}{l}-0.83 \\
\quad(-3.49,1.84)\end{array}$ & $\begin{array}{l}-2.17 \\
\quad(-6.45,2.10)\end{array}$ & $\begin{array}{l}0.23 \\
\quad(-4.20,4.67)\end{array}$ & $\begin{array}{l}0.37 \\
\quad(-1.90,2.64)\end{array}$ & $\begin{array}{l}0.29 \\
\quad(-2.07,2.64)\end{array}$ \\
\hline
\end{tabular}

${ }^{a}$ Adjusted regression model for age, gender and BMI

* $p$ Value statistically significant for $\alpha \leq 0.05$

differences have been developed and interact over time. Although our study was developed from a population-based study, we lost some participants for the analysis, which could determine a selection bias. Nevertheless, non-participants were quite similar to the studied population, with exception for gender and years of education.

Radiographic OA is likewise an imprecise guide to the likelihood that pain or disability will be present [10-12]. Notwithstanding, despite some limitations, our study supports the idea that the relation between radiographic OA, pain, function and quality of life is different between knee and hip joints. Correlation of radiographic severity, pain and disability in knee and hip OA is quite different between studies although in both cases literature is concordant in the poor correlation between radiographic score, pain and disability associated with OA both in the knee and hip [38-42]. The literature also tends to show that pain is more important than radiographic severity in determining disability $[9,42,43]$.

It is suggested that the pain, radiographic OA and quality of life may interact over time [11, 12]. For example, Laslett et al.

Table 5 Linear regression coefficients and $95 \%$ confidence intervals between radiographic score OA and Lequesne index, for knee and hip

\begin{tabular}{|c|c|c|c|c|c|c|c|c|}
\hline & \multicolumn{2}{|l|}{ Pain } & \multicolumn{2}{|c|}{ Walking distance } & \multicolumn{2}{|c|}{ Activities of daily living } & \multicolumn{2}{|l|}{ Total score } \\
\hline & $\begin{array}{l}\text { Crude } \beta \\
(95 \% \mathrm{CI}) \\
p \text { Value }\end{array}$ & $\begin{array}{l}\text { Adjusted } \beta^{\text {a }} \\
(95 \% \mathrm{CI}) \\
p \text { Value }\end{array}$ & $\begin{array}{l}\text { Crude } \beta \\
(95 \% \mathrm{CI}) \\
p \text { Value }\end{array}$ & $\begin{array}{l}\text { Adjusted } \beta^{\text {a }} \\
(95 \% \mathrm{CI}) \\
p \text { Value }\end{array}$ & $\begin{array}{l}\text { Crude } \beta \\
(95 \% \mathrm{CI}) \\
p \text { Value }\end{array}$ & $\begin{array}{l}\text { Adjusted } \beta^{\text {a }} \\
(95 \% \mathrm{CI}) \\
p \text { Value }\end{array}$ & $\begin{array}{l}\text { Crude } \beta \\
(95 \% \mathrm{CI}) \\
p \text { Value }\end{array}$ & $\begin{array}{l}\text { Adjusted } \beta^{\mathrm{a}} \\
(95 \% \mathrm{CI}) \\
p \text { Value }\end{array}$ \\
\hline \multirow[t]{3}{*}{ Knee radiographic score } & \multicolumn{8}{|c|}{ Knee Lequesne index } \\
\hline & 0.25 & 0.02 & 0.19 & 0.06 & $0.58^{*}$ & $0.48^{*}$ & $1.01 *$ & 0.56 \\
\hline & $(-0.22,0.71)$ & $(-0.48,0.52)$ & $(-0.15,0.53)$ & $(-0.32,0.43)$ & $(0.19,0.97)$ & $(0.08,0.89)$ & $(0.08,1.95)$ & $(-0.39,1.51)$ \\
\hline \multirow[t]{3}{*}{ Hip radiographic score } & \multicolumn{8}{|c|}{ Hip Lequesne index } \\
\hline & 0.03 & 0.63 & -0.38 & -0.25 & 0.46 & 0.46 & 0.17 & 0.84 \\
\hline & $(-2.56,2.61)$ & $(-1.64,2.89)$ & $(-2.02,1.25)$ & $(-1.76,1.27)$ & $(-1.83,2.75)$ & $(-1.41,2.34)$ & $(-5.35,5.70)$ & $(-3.63,5.31)$ \\
\hline
\end{tabular}

${ }^{\mathrm{a}}$ Adjusted regression model for age, gender and BMI

${ }^{*} p$ Value statistically significant for $\alpha \leq 0.05$ 
[44] suggests that associations between radiographic OA and quality of life may be mediated by pain, and this can in part explain the results described in Table 4.

These findings deserve clinical and epidemiological attention. From an epidemiologic point of view, the differences observed should be considered in the interpretation of data concerning prevalence and incidence estimates based on different OA definitions. From a clinical point of view, in different joints, radiographic features may be differently expressed as far as pain and function are concerned.

\section{Conclusions}

In the knee, an increase on radiographic score was associated with a higher pain frequency score and with worse general health, physical function, role-physical, bodily pain and limitations in activities of daily living. Regarding the hip, no significant associations were found between the severity of radiographic lesions and these measures.

Our data supports that the relation between radiographic OA features, pain, function and quality of life is different according to the joint considered which can influence OA case ascertainment and management.

\section{Compliance with ethical standards}

Disclosures None.

\section{References}

1. Felson DT (2009) Developments in the clinical understanding of osteoarthritis. Arthritis Res Ther 11(1):203. doi:10.1186/ar2531

2. Zhang W, Doherty M, Peat G, Bierma-Zeinstra MA, Arden NK, Bresnihan B et al (2010) EULAR evidence-based recommendations for the diagnosis of knee osteoarthritis. Ann Rheum Dis 69(3):483-489

3. Arden N, Nevitt MC (2006) Osteoarthritis: epidemiology. Best Pract Res Clin Rheumatol 20(1):3-25

4. Pereira D, Peleteiro B, Araujo J, Branco J, Santos RA, Ramos E (2011) The effect of osteoarthritis definition on prevalence and incidence estimates: a systematic review. Osteoarthr Cartil 19(11): 1270-1285

5. Duncan RC, Hay EM, Saklatvala J, Croft PR (2006) Prevalence of radiographic osteoarthritis - it all depends on your point of view. Rheumatology (Oxford) 45(6):757-760

6. Lawrence RC, Helmick CG, Arnett FC, Deyo RA, Felson DT, Giannini EH et al (1998) Estimates of the prevalence of arthritis and selected musculoskeletal disorders in the United States. Arthritis Rheum 41(5):778-799

7. Woolf A, Pfleger B (2003) Burden of major musculoskeletal conditions. Bull World Health Organ 81(9):646-656

8. Kinds MB, Welsing PM, Vignon EP, Bijlsma JW, Viergever MA, Marijnissen AC et al (2011) A systematic review of the association between radiographic and clinical osteoarthritis of hip and knee. Osteoarthr Cartil 19(7):768-778

9. McAlindon TE, Cooper C, Kirwan JR, Dieppe PA (1993) Determinants of disability in osteoarthritis of the knee. Ann Rheum Dis 52(4):258-262

10. Bedson J, Croft PR (2008) The discordance between clinical and radiographic knee osteoarthritis: a systematic search and summary of the literature. BMC Musculoskelet Disord 9:116. doi:10.1186/ 471-2474-9-116

11. Dahaghin S, Bierma-Zeinstra SM, Ginai AZ, Pols HA, Hazes JM, Koes BW (2005) Prevalence and pattern of radiographic hand osteoarthritis and association with pain and disability (the Rotterdam study). Ann Rheum Dis 64(5):682-687

12. Hannan MT, Felson DT, Pincus T (2000) Analysis of the discordance between radiographic changes and knee pain in osteoarthritis of the knee. J Rheumatol 27(6):1513-1517

13. Felson DT, Zhang Y (1998) An update on the epidemiology of knee and hip osteoarthritis with a view to prevention. Arthritis Rheum 41(8):1343-1355

14. Kopec JA, Rahman MM, Berthelot JM, Le Petit C, Aghajanian J, Sayre EC et al (2007) Descriptive epidemiology of osteoarthritis in British Columbia, Canada. J Rheumatol 34(2):386-393

15. Chan KKW, Wu RWK (2012) Symptoms, signs and quality of life $(\mathrm{QoL})$ in osteoarthritis (OA). In: Principles of osteoarthritis- its definition, character, derivation and modality-related recognition [internet]. Available from: http://www.intechopen.com/books/ principles-of-osteoarthritis-its-definition-character-derivation-andmodalityrelated-recognition/symptoms-signs-and-quality-of-lifeqol-in-osteoarthritis-oa

16. Creamer P, Lethbridge-Cejku M, Hochberg MC (1999) Determinants of pain severity in knee osteoarthritis: effect of demographic and psychosocial variables using 3 pain measures. $\mathrm{J}$ Rheumatol 26(8):1785-1792

17. Creamer P, Lethbridge-Cejku M, Hochberg MC (2000) Factors associated with functional impairment in symptomatic knee osteoarthritis. Rheumatology (Oxford) 39(5):490-496

18. Duncan R, Peat G, Thomas E, Hay E, McCall I, Croft P (2007) Symptoms and radiographic osteoarthritis: not as discordant as they are made out to be? Ann Rheum Dis 66(1):86-91

19. Ramos E, Lopes C, Barros H (2004) Investigating the effect of nonparticipation using a population-based case-control study on myocardial infarction. Ann Epidemiol 14(6):437-441

20. Huskisson EC (1982) Measurement of pain. J Rheumatol 9(5):768 769

21. Pereira D, Severo M, Ramos E, Branco J, Santos RA, Costa L et al (2015) Potential role of age, sex, body mass index and pain to identify patients with knee osteoarthritis. Int J Rheum Dis. doi:10. 1111/1756-185X.12611

22. Vaz-Serra A, Abreu J (1973) Aferição dos quadros clínicos depressivos: I. Ensaio de aplicação do inventário depressivo de beck a uma amostra Portuguesa de doentes deprimidos. Coimbra Med 20:623-644

23. Severo M, Santos AC, Lopes C, Barros H (2006) Reliability and validity in measuring physical and mental health construct of the Portuguese version of MOS SF-36. Acta Med Port 19(4):281-287

24. Lucas R, Rocha O, Bastos J, Costa L, Barros H, Lunet N (2009) Pharmacological management of osteoporosis and concomitant calcium supplementation in a Portuguese urban population: the EpiPorto study (2005-2007). Clin Exp Rheumatol 27(1):47-53

25. Dawson J, Linsell L, Doll H, Zondervan K, Rose P, Carr A et al (2005) Assessment of the Lequesne index of severity for osteoarthritis of the hip in an elderly population. Osteoarthr Cartil 13(10): 854-860

26. Faucher M, Poiraudeau S, Lefevre-Colau MM, Rannou F, Fermanian J, Revel M (2003) Assessment of the test-retest 
reliability and construct validity of a modified Lequesne index in knee osteoarthritis. Joint Bone Spine 70(6):521-525

27. LaValley MP, McLaughlin S, Goggins J, Gale D, Nevitt MC, Felson DT (2005) The lateral view radiograph for assessment of the tibiofemoral joint space in knee osteoarthritis: its reliability, sensitivity to change, and longitudinal validity. Arthritis Rheum 52(11):3542-3547

28. Auleley GR, Giraudeau B, Dougados M, Ravaud P (2000) Radiographic assessment of hip osteoarthritis progression: impact of reading procedures for longitudinal studies. Ann Rheum Dis 59(6):422-427

29. O’Reilly SC, Muir KR, Doherty M (1996) Screening for pain in knee osteoarthritis: which question? Ann Rheum Dis 55(12):931-933

30. Pereira D, Severo M, Barros H, Branco J, Santos RA, Ramos E (2013) The effect of depressive symptoms on the association between radiographic osteoarthritis and knee pain: a cross-sectional study. BMC Musculoskelet Disord 14:214

31. Kosinski M, Keller SD, Ware JE Jr, Hatoum HT, Kong SX (1999) The SF-36 health survey as a generic outcome measure in clinical trials of patients with osteoarthritis and rheumatoid arthritis: relative validity of scales in relation to clinical measures of arthritis severity. Med Care 37(5 Suppl):MS23-MS39

32. Davis MA, Ettinger WH, Neuhaus JM, Barclay JD, Segal MR (1992) Correlates of knee pain among US adults with and without radiographic knee osteoarthritis. J Rheumatol 19(12):1943-1949

33. Salaffi F, Carotti M, Stancati A, Grassi W (2005) Health-related quality of life in older adults with symptomatic hip and knee osteoarthritis: a comparison with matched healthy controls. Aging Clin Exp Res 17(4):255-263

34. Amaro A, Amado F, Duarte JA, Appell HJ (2007) Gluteus medius muscle atrophy is related to contralateral and ipsilateral hip joint osteoarthritis. Int J Sports Med 28(12):1035-1039

35. Duncan R, Peat G, Thomas E, Wood L, Hay E, Croft P (2008) How do pain and function vary with compartmental distribution and severity of radiographic knee osteoarthritis? Rheumatology (Oxford) 47(11):1704-1707

36. Hirsch R, Fernandes RJ, Pillemer SR, Hochberg MC, Lane NE, Altman RD et al (1998) Hip osteoarthritis prevalence estimates by three radiographic scoring systems. Arthritis Rheum 41(2):361-368

37. Gunther KP, Sun Y (1999) Reliability of radiographic assessment in hip and knee osteoarthritis. Osteoarthr Cartil 7(2):239-246

38. Barker K, Lamb SE, Toye F, Jackson S, Barrington S (2004) Association between radiographic joint space narrowing, function, pain and muscle power in severe osteoarthritis of the knee. Clin Rehabil 18(7):793-800

39. Salaffi F, Cavalieri F, Nolli M, Ferraccioli G (1991) Analysis of disability in knee osteoarthritis. Relationship with age and psychological variables but not with radiographic score. J Rheumatol 18(10):1581-1586

40. Summers MN, Haley WE, Reveille JD, Alarcon GS (1988) Radiographic assessment and psychologic variables as predictors of pain and functional impairment in osteoarthritis of the knee or hip. Arthritis Rheum 31(2):204-209

41. Szebenyi B, Hollander AP, Dieppe P, Quilty B, Duddy J, Clarke S et al (2006) Associations between pain, function, and radiographic features in osteoarthritis of the knee. Arthritis Rheum 54(1):230-235

42. van Baar ME, Dekker J, Lemmens JA, Oostendorp RA, Bijlsma JW (1998) Pain and disability in patients with osteoarthritis of hip or knee: the relationship with articular, kinesiological, and psychological characteristics. J Rheumatol 25(1):125-133

43. Parmelee PA, Harralson TL, McPherron JA, DeCoster J, Schumacher HR (2012) Pain, disability, and depression in osteoarthritis: effects of race and sex. J Aging Health 24(1):168-187

44. Laslett LL, Quinn SJ, Winzenberg TM, Sanderson K, Cicuttini F, Jones $\mathrm{G}$ (2012) A prospective study of the impact of musculoskeletal pain and radiographic osteoarthritis on health related quality of life in community dwelling older people. BMC Musculoskelet Disord 13:168 